\section{G349(P) SPECTRUM OF PAEDIATRIC TRAUMATIC BRAIN INJURY PRESENTING TO TERTIARY PAEDIATRIC EMERGENCY DEPARTMENTS}

${ }^{1,2}$ E Ryan, ${ }^{3}$ I Okafor, ${ }^{4} \mathrm{C}$ Blackburn, ${ }^{4} \mathrm{M}$ Barrett, ${ }^{1} \mathrm{~T}$ Bolger, 1,2 E Molloy, ${ }^{1}$ Paediatrics, National, Children's Hospital, Tallaght, Dublin, Ireland; ${ }^{2}$ Paediatrics, Dublin University, Trinity College Dublin, Dublin, Ireland; ' ${ }^{3}$ Emergency Department, Children's University Hospital, Temple Street, Dublin, Ireland; ${ }^{4}$ Emergency Department, Our Lady's Hospital for Sick Children, Crumlin, Dublin, Ireland

10.1136/archdischild-2018-rcpch.339

Aims To determine the burden and aetiology of traumatic brain injuries (TBIs) presenting to tertiary paediatric emergency departments (PEDs). To determine the number of TBIs that are symptomatic, requiring imaging, re-presenting and requiring admission.

Methods Retrospective analysis of presentations of children 0$16 \mathrm{y}$ to the 3 Paediatric Emergency Departments (PEDs) in a large urban area for 24 months. Diagnoses of head injury, intracranial bleed, skull fracture and those re-attending with the same complaint within 28 days were included. Hospital Symphony Emergency Department Information System (EDIS) and radiology (NIMIS) information systems were interrogated. Demographics, mechanism of injury, CT ordering and discharge destination were recorded. Demographic Data was extracted from the 2016 national census.

Results Head injury was diagnosed in 13336 of 224860 (5.9\%) presentations to PEDs over 24 months. Median (range) age of presentation was $5.3(0-16)$ years. The age profile was: Infants, $\mathrm{n}=1705$ (12.8\%), preschool age, $\mathrm{n}=6424$ (48.2\%) primary school age, $\mathrm{n}=3673$ (27.6\%), adolescents 12-16 y, $\mathrm{n}=1970$ (14.8\%). In adolescents, males predominant $(73 \%)$ but gender equal in other age-groups. The rate of presentation is $3.7 \%$ per year at preschool age.

Number admitted, transferred or reviewed was $n=1460$ $(10.8 \%)$ with a neuroimaging rate of $4.4 \%$. The triage category was 4 in $6718(50 \%)$ and the place of accident was known in $\mathrm{n}=5298$ (39.5\%). Accidents occurred at home $\mathrm{n}=3325(62.7 \%)$.

In those with known mechanisms (52\%), falls were predominant; $n=3315$ (47.5\%) particularly from a height $(n=1925)$ including from beds $(n=298)$. Rugby alone accounts for a small number, $n=229$ (3.26\%), but $n=190$ (18.4\%) of the adolescent group.

Conclusion Preschool children have the highest incidence of head injury and the majority of injuries follow a fall. Sport accounts for a significant number of injuries in older children. Standardised reporting would improve information on demographics and mechanisms and allow targeted interventions in each age-group.

\section{G350(P) IMPROVING DISCHARGE PLANNING FOR CHILDREN PRESENTING TO THE EMERGENCY DEPARTMENT WITH WHEEZE}

${ }^{1} \mathrm{~A}$ Downes, ${ }^{1} \mathrm{~S}$ Davies, ${ }^{2} \mathrm{~S}$ Thenabadu. ${ }^{1}$ Paediatrics, Princess Royal University Hospital, King's College NHS Foundation Trust, London, UK; ${ }^{2}$ Emergency Medicine, Princess Royal University Hospital, King's College NHS Foundation Trust, London, UK

\subsection{6/archdischild-2018-rcpch.340}

Objectives and background Childhood wheeze is a common presentation in the emergency department. The National Review for Asthma Deaths has identified that there are still significant shortcomings in the acute and chronic care of asthma and wheeze in the UK. A 'Wheeze Clerking Proforma' (WCP) was introduced in the ED of a busy district general hospital to improve information gathering, acute management and discharge planning, according to recommended standards, with a view to improving overall outcomes. There were immediate improvements in clerking and acute management with the introduction of the WCP, however discharge planning remained unsatisfactory.

To improve discharge planning, the WCP was redesigned to increase emphasis on discharge and to encourage parents to instigate completion of the 'discharge checklist'. A retrospective case note audit was conducted to determine the success of this approach.

Methods Children aged 1-16 attending with wheeze from 01/ $05 / 2017$ to $14 / 05 / 0217$ and $05 / 06 / 2017$ to $17 / 06 / 2017$ were identified from a manual search of ED patient records.

Information was collected on patient demographics, wheezespecific information gathering, acute treatment and discharge outcomes.

Data were analysed using Microsoft Excel.

Results 66 eligible children were identified; 58\% were clerked on WCPs. Information gathering for children on WCPs was superior in all domains. All children received appropriate acute treatment.

29 children were discharged, 11 of whom had WCPs. These children were more likely to have inhaler technique checked (45\% vs 6\%), receive an emergency action plan (36\% vs $0 \%$ ), be advised to see the GP within 48 hours (45\% vs 17\%) and have appropriate follow-up arranged (18\% vs 6\%).

Conclusions Placing more emphasis on discharge planning and encouraging parents to engage in this process has improved discharge outcomes in the $\mathrm{ED}$, although there remains room for improvement.

\section{G351(P) HIGH FALLS FROM WINDOWS AND BALCONIES IN CHILDREN (2006-2011)}

SP Lewis, AJ Nicholson. Department of Paediatrics, Temple St Children's University Hospital, Dublin, Ireland

\subsection{6/archdischild-2018-rcpch.341}

Aims Young children are at risk of falls due to their lack of danger awareness and curious nature. Falls from heights more than two metres are associated with significant risk of death and disability and contributed to $2.7 \%$ of injury-related deaths in Ireland between 2006-2011. The aim of this study was to further explore falls from windows and balconies, to identify demographics, injury type and severity, long-term outcomes and to inform strategies for prevention.

Methods This retrospective cohort study reviewed high falls from windows and balconies in children from 2010 to 2016 in Ireland. Data was obtained from submissions to the Trauma Audit and Research Network (TARN) database and analysed in Excel. ${ }^{1,2}$

Results Seventy-six high falls were recorded during the study period with twenty falls occurring from a window or balcony. Of these twenty children, eighteen were less than five years, with a median age of 2 years (range 1.0-7.6 years) and a male to female ratio of $2.3: 1$. In this patient cohort, there were two deaths, four children sustained moderate disability and fourteen had a good recovery according to Glasgow 